\title{
Evidence for early human occupation at high altitudes in western Central Asia: the Alay site
}

\author{
Svetlana Shnaider ${ }^{1,2, *}$, William T. Taylor ${ }^{2}$, Aida Abdykanova ${ }^{3}$, \\ Ksenia Kolobova $^{1} \&$ Andrei Krivoshapkin $^{1}$
}

The Alay site represents the earliest, high-altitude human-occupation site currently known in western Central Asia. Recent recovery and analysis of a lithic assemblage from Alay underlines the importance of this site and its role in the cultural and technological development in later Eurasian prehistory.

Recent research suggests that humans first occupied high mountain regions during the Final Pleistocene and Early Holocene. Some of the earliest high-altitude sites $(4000 \mathrm{~m}$ asl and above) found in the Andes date to around 10kya, and to approximately $13 \mathrm{kya}$ in Tibet and the Himalayas (Meyer et al. 2017). Bracketed by the Himalayas and the Tibetan Plateau, western Central Asia was a probable migration route for early peoples moving into North and East Asia (Bae et al. 2017). The area also channelled cultural and technological influence, and facilitated exchange between adjoining regions in later prehistory, most famously as part of the Silk Roads (Christian 2000). As many culturally and economically significant areas of this region lie above $2000 \mathrm{~m}$ asl, it is essential to characterise the timing and nature of human exploitation of the high-altitude continental interior, in order to understand the human history in Eurasia.

Western Central Asia has several high mountain regions, including the Tian Shan (2000$5000 \mathrm{~m}$ asl), the Pamir Mountains (3000-4500m asl) and the Alay Range (2300-3500m asl). Previous archaeological research in the Central Asian high mountains discovered several Epipalaeolithic sites in the Pamir region, including the Oshhona open-air site (4000m asl) and Istikskaya Cave $(4000 \mathrm{~m}$ asl), and the Markansu River Valley in Tajikistan (Ranov 1988).

Only one Palaeolithic site has been documented in the Alay Valley. Known as the Alay site, it is located in the western part of the Alay Valley, on the banks of the Kyzyl-Suu River, at an elevation of $2800 \mathrm{~m}$ (Figures 1 \& 2). It was discovered in 1975 by A.A. Nikonov, who conducted several seasons of field survey. More than 1740 lithic artefacts were recovered, analysis of which revealed prismatic and narrow-faced blades and bladelets,

1 Institute of Archaeology and Ethnography of the Siberian Branch of the Russian Academy of Sciences, 17, Academician Lavrentiev Avenue, Novosibirsk 630090, Russia

2 Max Planck Institute for the Science of Human History, Kablaische Strasse 10, D-07745 Jena, Germany

3 American University of Central Asia, 7/6 Aaly Tokombaev Street, Bishkek 720060, Kyrgyz Republic

* Author for correspondence (Email: sveta.shnayder@gmail.com)

(C) Antiquity Publications Ltd, 2018

ANTIQUITY 92 363, e1 (2018): 1-7

https://doi.org/10.15184/aqy.2018.94 


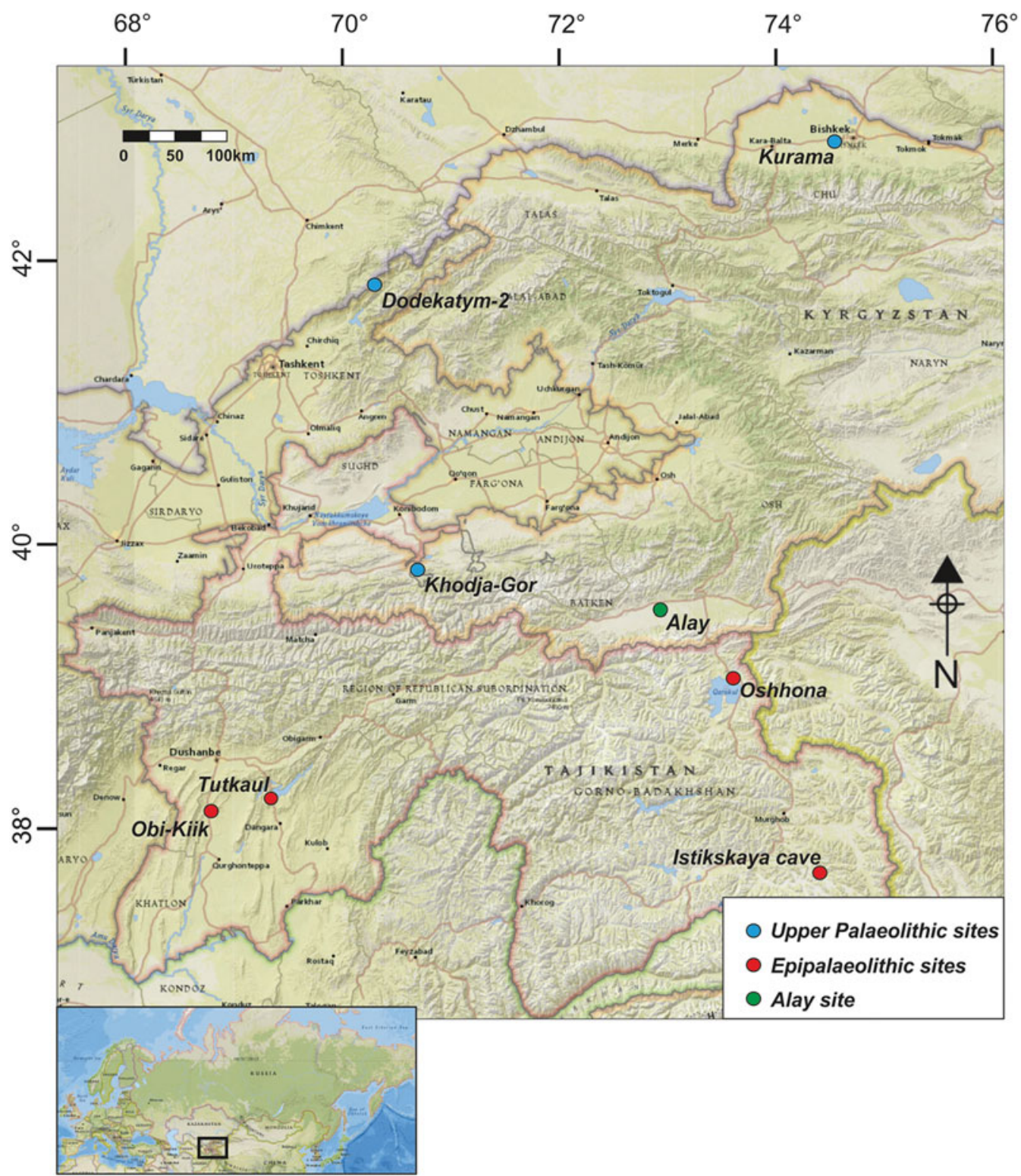

Figure 1. The location of archaeological sites mentioned in the article. Map produced using National Geographic Basemap using ArcGIS Online.

end-scrapers, notched pieces, awls and backed points on blades. The lithic industry was typologically dated to the Early Holocene, and is hypothesised to be synchronous with other materials from Pamir (the Oshhona site and Istikskaya Cave) (Ranov et al. 2015). As the only evidence for early human occupation at high altitude in this key region of southern Kyrgyzstan, this site is of immense significance to our understanding of human lifeways in Central Asian prehistory.

(C) Antiquity Publications Ltd, 2018 

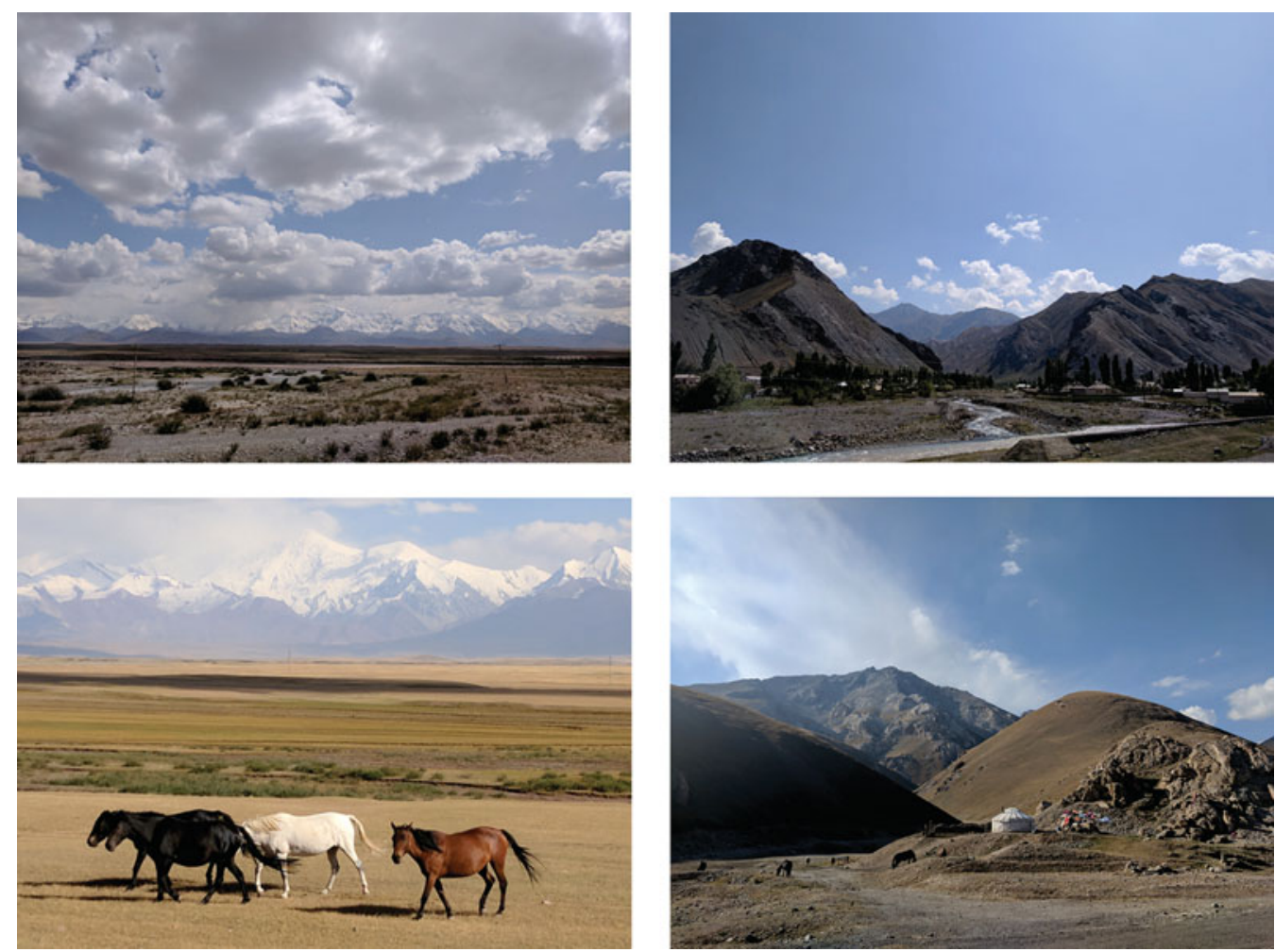

Figure 2. Alay Valley, Kyrgyzstan. Photographs by W. Taylor.

Our international expedition returned to the Alay site (Figure 3) in 2017. Three test pits were dug in different areas of the site in order to clarify its stratigraphy and lateral extent (Figures 4 \& 5: 4). These confirmed that much of the cultural layer of the site is currently exposed, with material including charcoal, bones and lithics visible on the surface. We collected all materials from an artefact-dense $25 \mathrm{~m}^{2}$ area (Figure 5: $1-3$ ). The stone artefact assemblage from this area comprises 244 specimens, the majority of which is debitage ( $\mathrm{n}=$ 156; 64 per cent). We identified two morphologically distinct core types: semi-cylindrical with one striking platform (Figure 6:9), and semi-pyramidal with two striking platforms for bladelets (Figure 6: 7). Core-preparation blanks included semi-tablets, a corner spall, front core-trimming spalls and one lateral spall, while in the blank category we identified 47 flakes, 14 blades (Figure 6: 6) and 13 bladelets (Figure 6: 2).

Blank production at the Alay site appears to have been focused on the manufacture of blades and bladelets that are morphologically similar and result from a specialised blankproduction system. The blanks that we recovered were extremely fragmented. The length of whole blades varies from $30-50 \mathrm{~mm}$, and the width from $12-23 \mathrm{~mm}$, with most falling between 13 and $16 \mathrm{~mm}$. Only four whole bladelets were identified, ranging in length from $15-21 \mathrm{~mm}$, with a width for most bladelets between 6 and $9 \mathrm{~mm}$. Blades and bladelets show predominantly unidirectional parallel dorsal scar patterns, with parallel lateral edges, trapezoidal to triangular midpoint cross sections, and straight longitudinal profiles. Most 


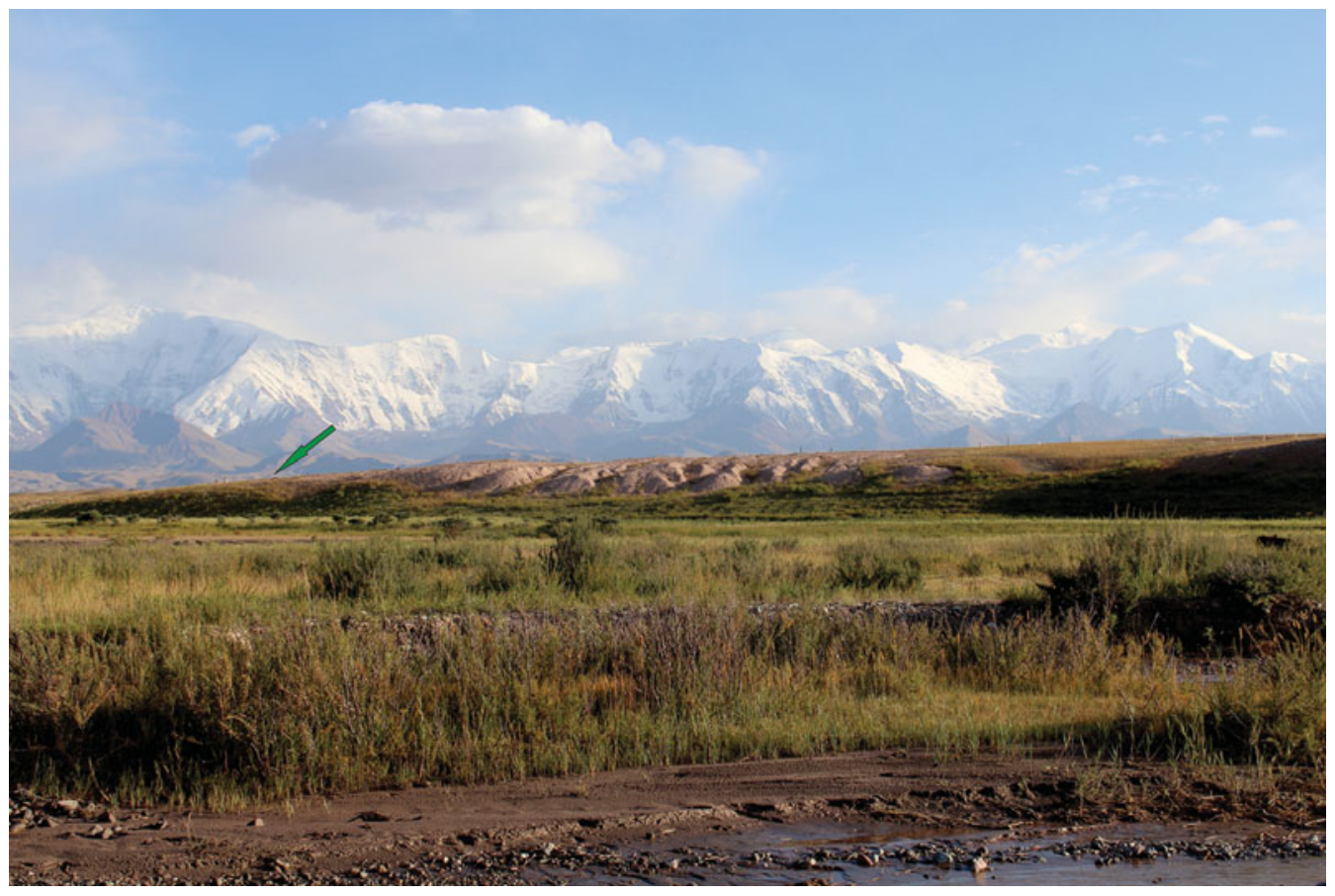

Figure 3. View of the Alay site from the east (indicated by green arrow). Photograph by W. Taylor.

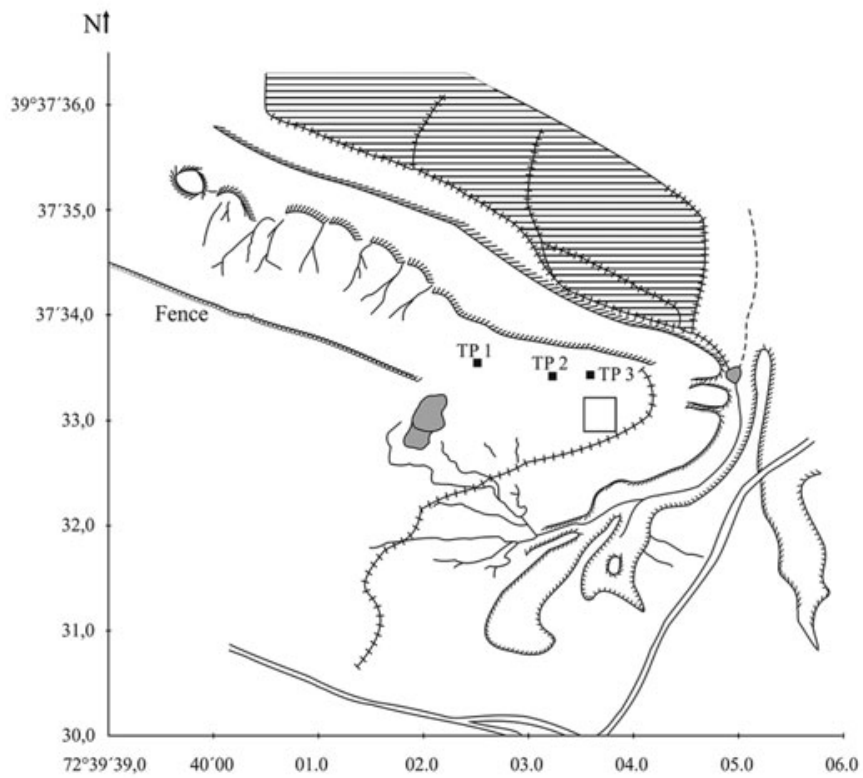

Legend:

き Irrigated wheat field

Slope

Fence

- Test pit

- Area of artefact collection

/I Road

H+1+H Manmade irrigation ditch

Manmade .../pond/...

$\therefore$ Former channel

7 Erosional rill

Figure 4. Map of the Alay site (by W. Taylor).

(C) Antiquity Publications Ltd, 2018 

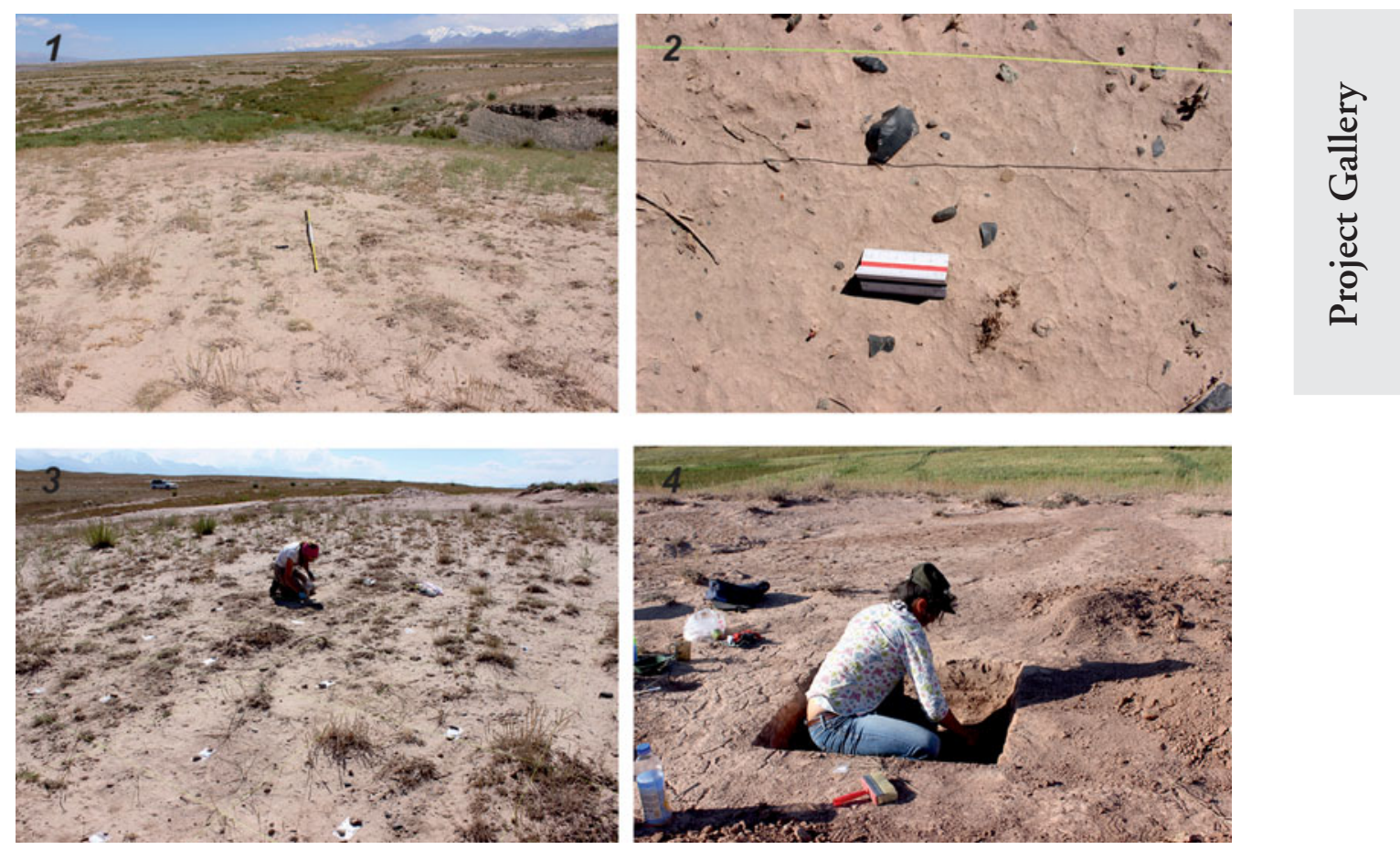

Figure 5. Excavations at the Alay site, 2017: 1) area of artefact collection; 2) example showing artefact distribution; 3) artefact collection; 4): test pit at the Alay site. Photographs by A. Abdykanova.

blades have a reduced, flat striking platform, while a few bladelets have a linear platform. These characteristics are indicative of a recurrent unidirectional production system. All blades and bladelets with a proximal edge show lips and small percussion damage, indicative of soft-hammer flaking. These characteristics suggest that Alay occupants used the same strategy to produce both blades and bladelets. The tool assemblage totals 17 specimens, most of which are end-scrapers (Figure 6: $4 \& 8$ ) and notched pieces, although the collection also includes awls, backed bladelets (Figure 6: 1), flakes (Figure 6:5) and blades (Figure 6: 3) with utilisation retouch. Blades appear to have served as blanks for most of the tool types recovered from the Alay site.

This analysis challenges the analogy drawn between the Alay site and other materials recovered from high-altitude sites in Pamir. Our recent reanalysis of the stone artefact collections from the Oshhona and Istikskaya cave sites demonstrates that these assemblages were produced through the microblade knapping; microblades with ventral retouch and 'thumbnail' end-scrapers dominated the assemblages. This industry dates to between 137 kya BP (Shnaider et al. 2017). Major technological and typological differences with the Alay assemblage suggest that the Oshhona and Istikskaya materials may represent a different cultural or technological tradition. In contrast, the Alay stone tool assemblage shows many similarities with the late stage of the 'Kulbulakian' (represented by Dodekatym-2) and early and middle 'Tutkaulian' (represented by Tutkaul, 1.3, Obi-Kiik) cultures found in post-Late Glacial Maximum assemblages from the Tian-Shan and Hissaro-Alay regions (Kolobova

(C) Antiquity Publications Ltd, 2018 
Svetlana Shnaider et al.
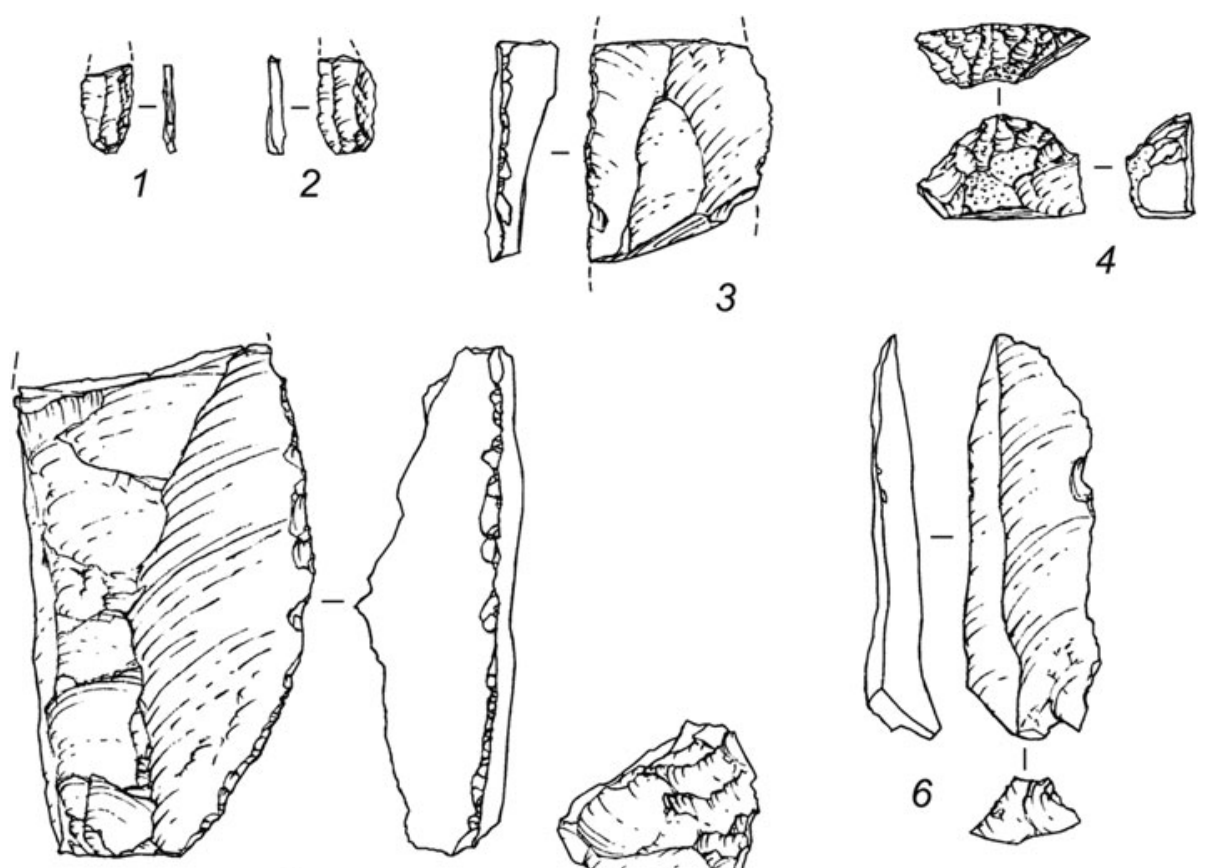

5

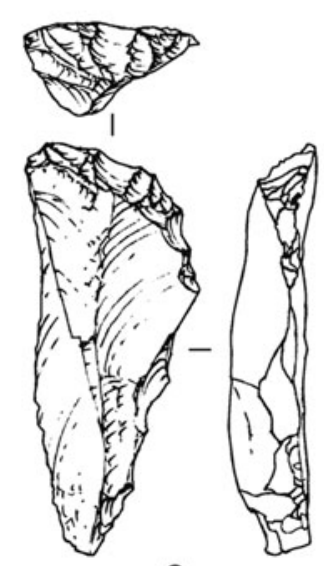

8

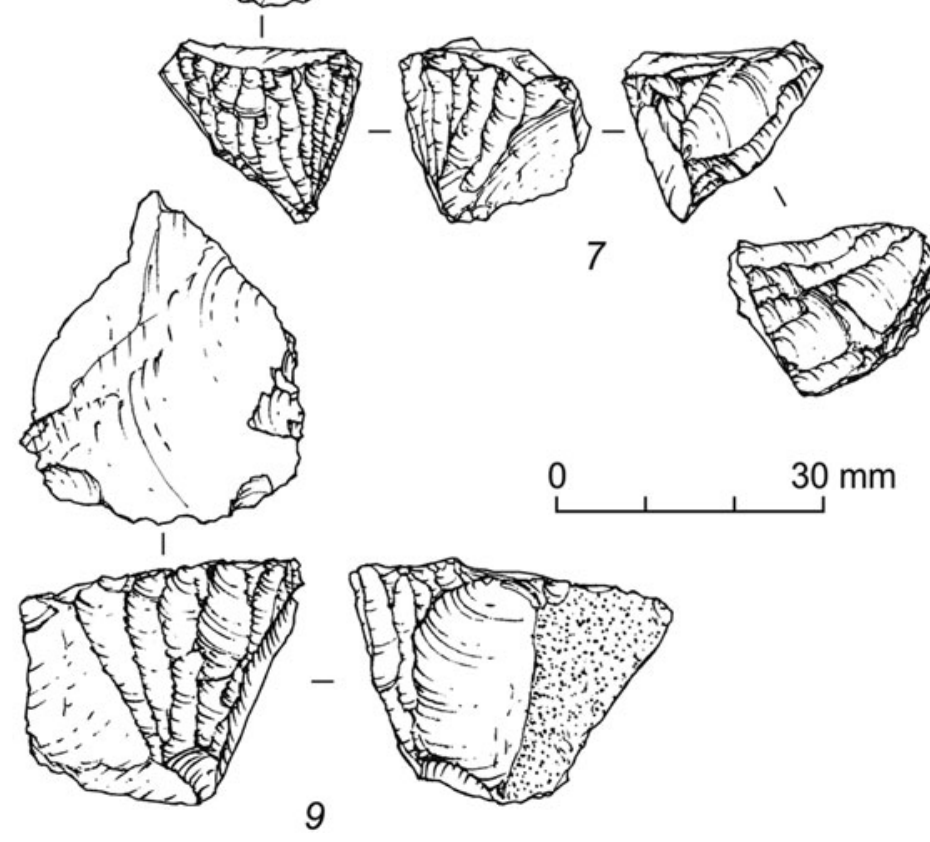

Figure 6. Lithic artefacts from the Alay site.

(C) Antiquity Publications Ltd, 2018 
et al. 2016), as well as with Upper Palaeolithic industries, such as Khodja-Gor and Kurama. As with the Alay lithic assemblage, these industries are also characterised by blade/bladelet knapping with soft-hammer flaking, along with similar types of tools, such as end-scrapers, notched pieces and backed bladelets.

A more detailed cultural and chronological characterisation of the Alay site will only be possible through new excavations aimed at obtaining a larger archaeological assemblage and material for absolute dating. These efforts will illuminate the economy of Central Asia's first high-altitude foragers and their role in the movements, exchanges and cultural developments that shaped the prehistory of the continental interior. Nevertheless, key technological differences with assemblages from the nearby Pamir Mountains hint at an affiliation with the Final Palaeolithic complexes of western Central Asia. They may also confirm that the Alay site represents the earliest episode of high-altitude occupation in the region.

\section{Acknowledgements}

The research was supported by a project of the Institute of Archaeology and Ethnography (SB RAS 0329-20160002).

\section{References}

Bae, C.J., K. Douka \& M. Petraglia. 2017. On the origin of modern humans: Asian perspectives. Science 358. https://doi.org/10.1126/science.aai9067

Christian, D. 2000. Silk roads or steppe roads? The Silk Roads in world history. Journal of World History 11: 1-26. https://doi.org/10.1353/jwh.2000.0004

Kolobova, K.A., S.V. Shnaider \& A.I. Krivoshapkin. 2016. Continuous development of the Upper Paleolithic and Mesolithic industries in western Central Asia. Stratum Plus 1: 51-63.

Meyer, M.C., M.S. Aldenderfer, Z. Wang, D.L. Hoffmann, J.A. Dahl, D. Degering, W.R. HaAs \& F. SchlÜtz. 2017. Permanent human occupation of the central Tibetan Plateau in the Early Holocene. Science 355: 64-67. https://doi.org/10.1126/science.aag0357
Ranov, V.A. 1988. Stone Age of southern Tajikistan and Pamir. PhD dissertation, Novosibirsk, Institute of History, Philology and Philosophy. Novosibirsk: IAET SO RAN

Ranov, V.A., T.G. Filimonova \& A.A. Nikonov. 2015. Alay site, in A.P. Derevianko \& M.V. Shun'kov (ed.) Coming back to beginnings: 196-206. Novosibirsk: IAET SO RAN.

Shnaider, S.V., M.T. Krajcarz, T.B. Viola, A. Abdykanova, K.A. Kolobova, A. Yu. Fedorchenko, S. Alisher-Kyzy \& A.I. Krivoshapkin. 2017. New investigations of Epipalaeolithic in western Central Asia: Obishir-5. Antiquity Project Gallery 91(360). https://doi.org/10.15184/aqy.2017.213 